\title{
Voltage Regulation Control with Adaptive Fuzzy Logic for a Stand-Alone Photovoltaic System
}

\author{
Claude Bertin Nzoundja Fapi ${ }^{1,2 *}$, Patrice Wira ${ }^{2}$, Martin Kamta $^{1}$, Bruno Colicchio ${ }^{2}$ \\ ${ }^{1}$ LESIA Laboratory, University of Ngaoundere, Ngaoundere 455, Cameroon \\ ${ }^{2}$ IRIMAS Laboratory, University of Haute Alsace, 61 Road Albert Camus, Mulhouse 68200, France
}

Corresponding Author Email: claude.nzoundja@uha.fr

https://doi.org/10.18280/ejee.220208

Received: 20 January 2020

Accepted: 8 March 2020

\section{Keywords:}

voltage control, fuzzy logic controller, MPPT algorithms, photovoltaic panel, DC-DC converter

\begin{abstract}
Electronic circuits suitable for converting, controlling and conditioning electrical energy in solar applications are required to ensure efficient use of the solar system. This paper proposes a stand-alone system consisting of a Maximum Power Point Tracking (MPPT) algorithm and a fuzzy logic based voltage controller for a photovoltaic application. The fuzzy logic-based intelligent algorithm MPPT controls the DC-DC boost converter to find the best Maximum Power Point (MPP) with speed and accuracy without steady state oscillations under variable methodological conditions (irradiance and temperature). The fuzzy logic-based voltage controller is designed using the T-Standards and the standardization process to improve transient control performance. Voltage Regulation Control with Adaptive Fuzzy Logic for a Stand-alone Photovoltaic System is designed and simulated in the MatLab/Simulink environment. The results show that the fuzzy controller effectively resolves system voltage instability by keeping the DC-DC buck converter voltage constant despite variable weather and load conditions.
\end{abstract}

\section{INTRODUCTION}

The efficient use of photovoltaic (PV) solar energy requires electronic circuits associated with the conversion, control and conditioning of electrical energy. Particular emphasis is placed on the search for highly efficient converter topologies and the design of control mechanisms to meet the objectives of the latter $[1,2]$. However, the low conversion efficiency of solar cells is a particularly associated disadvantage and depends on weather conditions and the applied load [3-5]. Therefore, to increase the efficiency of a stand-alone PV system dedicated to grid connection or storage, the latter must be used at its Maximum Power Point (MPP) and associated with a voltage regulation system to solve the problem of voltage fluctuation [5-7].

In the first aspect, many Maximum Power Point Tracking (MPPT) methods have been developed to track the MPP. These include Perturb and Observe (P\&O) [8], Incremental of Conductance (INC) [9], Hill Climbing (HC) [10], Fuzzy Logic Controller (FLC) [7, 11] and Neural Network (NN) [7, 11]. These methods vary in convergence speed, oscillations around the MPP, complexity of implementation algorithms, calculation costs and electronic requirements. The FLC-based MPPT method is preferred in this study. Indeed, this method is faster in terms of stabilization time, in changing weather conditions and this without affecting the circuit parameters [2$5,11]$. In addition, it is accurate, oscillates less and gives the best result to find changes in the MPP $[7,11]$.

With regard to the fluctuation of the voltage at the output of the DC-DC converter, two control structures can be used. Current mode control, consisting of two interlocking closedloop systems; the internal system is a current control system, while the external system is a voltage control system [12-17].
The feasibility of the interlocking control system requires that the internal control is relatively faster. In addition, it stabilizes the unstable zero dynamic range, allowing the usual control designs to be applied. However, the performance of the control system may be poor when working outside the nominal operating conditions. Fuzzy Logic controllers have been used in the researched $[12,13]$ without any guarantee of stability and performance for simultaneous variation of source and load. The second approach is voltage control, which is based on direct control of the output voltage without using the current control system or stabilizing the dynamics of unstable zeros. A common technique is to use the linearized model of the system, valid in a vicinity of the nominal point, with its uncertainties, if necessary. The automatic setting of the PID was taken into account in the studies $[16,17]$. The extended linearization with integral-proportional (IP) and (PI) controller was continued in the study [18] and the predictive control of the model was considered by Pathak and Yadav [19]. Although these approaches increase robustness and performance at high disturbances, they would have poor performance throughout the workspace and could lead to unexpected behavior.

In this paper, adaptive voltage control in Fuzzy Logic is proposed for a stand-alone photovoltaic system illustrated in Figure 1. The block diagram of the stand-alone photovoltaic system consists of a solar panel as the power source for the system. Then, the first DC-DC Boost converter with its MPPT control provides the maximum available power and serves as an interface between the solar panel and the next converter. And finally, the second Buck DC-DC converter with its fuzzy logic based voltage regulator serves as an interface between the variable load and the previous converter. The converter with its MPPT control uses the $V_{p v}$ voltage and $I_{p v}$ current 


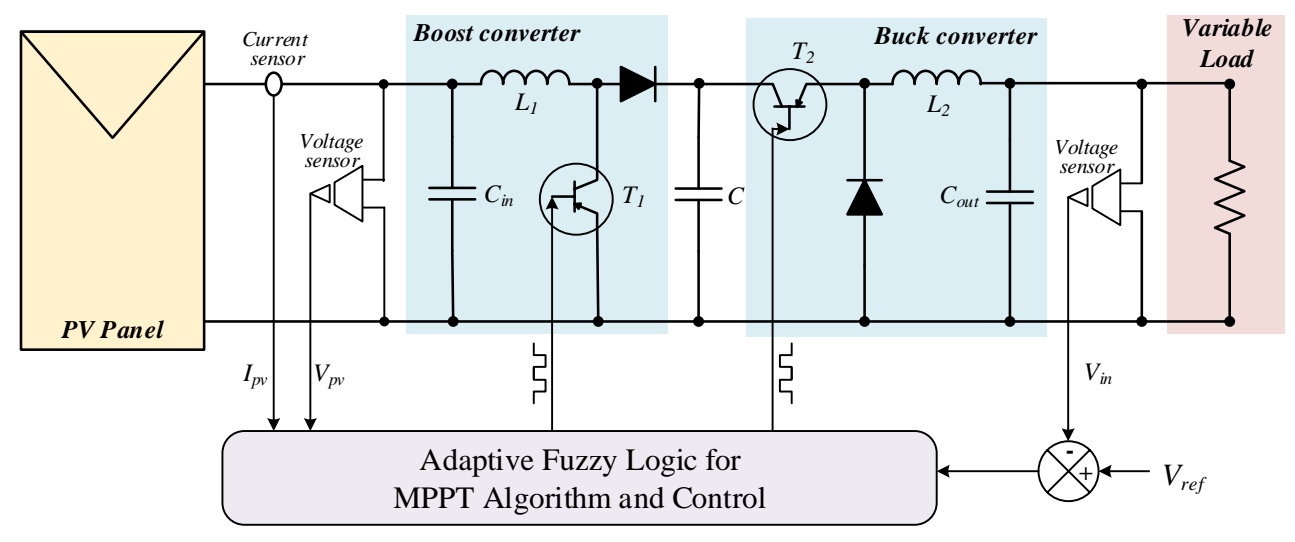

Figure 1. PV system MPPT algorithm and voltage control with fuzzy logic

supplied by the PV module as inputs. Then the Pulse Width Modulation (PWM) signal generated by the Maximum Power Point Tracking (MPPT) control is used to drive the DC-DC boost converter. The voltage control based on fuzzy logic uses the voltage supplied by the Buck DC-DC converter and the voltage reference to generate the PWM signal to drive the Buck DC-DC converter.

The objective is to use this stand-alone photovoltaic (PV) system at its Maximum Power Point (MPP) and through fuzzy logic control, provide a constant voltage at the output of the DC-DC converter, regardless of weather conditions and variable load. We design a Fuzzy Logic Controller based on the knowledge of the latter's techniques according to which its transient control performance is improved if we act simultaneously on the T-Standards and the standardization process. By using Fuzzy Logic implication interpreted as a conjunction and the Integral type optimization criterion of the absolute error, absolute value between the set point applied to the system and the measured output variable (in this case, voltage of the DC-DC Buck converter), we derive a stability condition of the closed loop control system that can be used to adjust its parameters.

This document is structured as follows: the PV system architecture and the preference, modeling of converters are described in Section 2. Subsequently in Section 3, the adaptive Fuzzy Logic based MPPT algorithm and control design of the converter is presented. The results of the simulation and discussions are given in Section 4. The conclusion summarizing the salient points is presented at the end of the document.

\section{PV SYSTEM ARCHITECTURE}

A photovoltaic (PV) system is mainly composed of a PV module, a converter and a load. This system produces DC voltage and current that is ideal for certain applications, such as battery charging. The converters that are used as an interface maintain the operating point of the PV system at Maximum Power Point (MPP) using Maximum Power Point Tracking (MPPT) algorithms.

\subsection{PV model and characteristics}

The circuit in Figure 2 represents the equivalent scheme of a PV cell [15]. Usually composed of a diode and two resistors (series $R_{s}$ and parallel $R_{p}$ ), in the presence of ambient light, it produces electrical current through the photovoltaic effect.

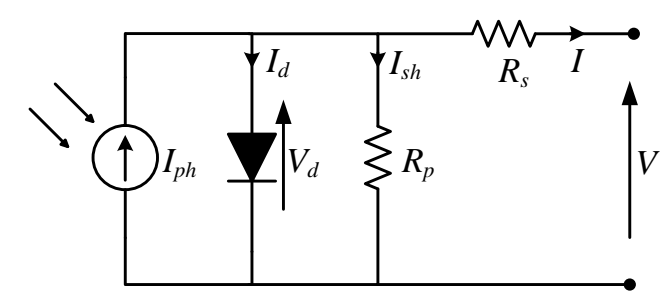

Figure 2. Electric model equivalent to a PV cell

The current generated by the cell of Eq. (1) is then determined by applying Kirchhoff's rules in Figure 2.

$$
I=I_{p h}-I_{o}\left[\exp \left(\frac{V+R_{s} I}{a N_{s c} V_{t}}\right)-1\right]-\frac{V+R_{s} I}{R_{s h}}
$$

where, $V$ is the output voltage across the PV panel, $a$ is the diode ideality factor, $V_{t}$ is the thermal voltage $\left(V_{t}=K T / q\right), K$ is the Boltzmann constant, $q$ is the electron charge. The photo generated current is expressed as:

$$
I_{p h}=\left[I_{s c}+K_{i}\left(T-T_{n}\right)\right] G / G_{n}
$$

where, $I_{s c}$ is the PV cell's short-circuit current, $K_{i}$ is the current coefficient, $T, G, G_{n}$ and $T_{n}$ are respectively, the actual temperature, actual irradiation, nominal irradiation and nominal temperature. The diode reverse saturation current is given by:

$$
I_{o}=\frac{I_{s c}+K_{i}\left(T-T_{n}\right)}{\exp \left[\left(V_{o c}+K_{v} \Delta T\right) / n N_{s c} V_{t}\right]-1}
$$

where, $V_{o c}$ is the cell's open-circuit voltage at the nominal conditions and $K_{v}$ is the voltage coefficient.

The Solkar36w PV panel used in our study is of the noncrystalline silicon type. It produces a power of $40 \mathrm{~W}$ under Standard Test Conditions (STC: $1000 \mathrm{~W} / \mathrm{m}^{2}$ and $25^{\circ} \mathrm{C}$ ). The numerical data for the simulation are listed in Table 1 [15].

The current-voltage $(I-V)$ and power-voltage $(P-V)$ characteristics of solar photovoltaic (PV) modules under STC conditions are the basic requirements for monitoring the Maximum Power Point (MPP) using one of the Maximum Power Point Tracking (MPPT) algorithms. Therefore, the single-diode photovoltaic (PV) cell electrical circuit of Figure 1 with Eqns. (1), (2) and (3) are used to simulate the characteristic curves of the Solkar36w PV panel of Figure 3 in 
the MatLab/Simulink environment. As shown in Figure 3, there are individual points on the $\mathrm{I}-\mathrm{V}$ and $\mathrm{P}-\mathrm{V}$ characteristics of the PV panel for $\mathrm{G}=1000 \mathrm{~W} / \mathrm{m}^{2}$ and $\mathrm{T}=25^{\circ} \mathrm{C}$, which are recognized as the maximum power $\left(P_{m p p}\right)$, maximum voltage $\left(V_{m p p}\right)$ and maximum current $\left(I_{m p p}\right)$ corresponding to the Maximum Power Point. In order to produce the highest power, regardless of solar radiation and temperature, the operating point of the PV module must correspond to the maximum value of the $I-V$ or $P-V$ curve.

Table 1. Solkar36w PV panel numerical data

\begin{tabular}{ccc}
\hline Parameters & Symbols & Values \\
\hline Maximum power & $P_{m p p}(W)$ & 37.08 \\
Maximum voltage & $V_{m p p}(V)$ & 16.56 \\
Maximum current & $I_{m p p}(A)$ & 2.25 \\
Open-circuit voltage & $V_{o c}(V)$ & 21.24 \\
Short-circuit current & $I_{s c}(A)$ & 2.55 \\
Voltage coefficient & $K_{v}(V / K)$ & -1.0017 \\
Current coefficient & $K_{i}(A / K)$ & 0.032 \\
\hline
\end{tabular}

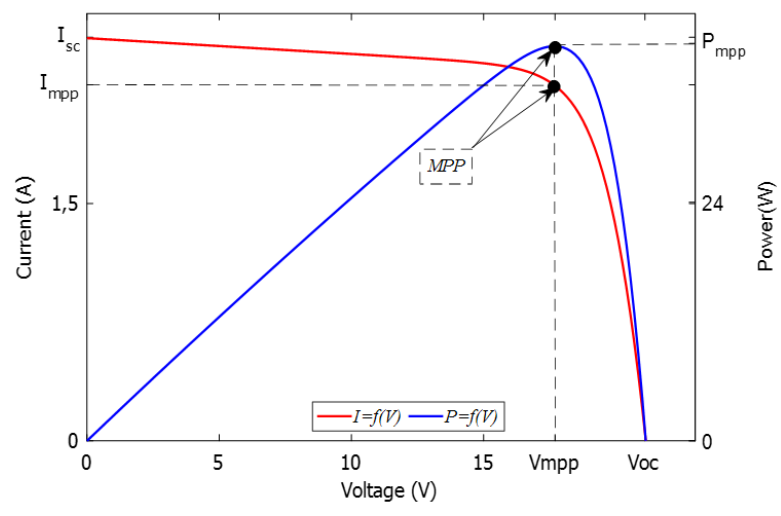

Figure 3. Characteristic curves of the solkar36w PV panel

\subsection{Preference and Modeling of converters}

The design of a DC-DC adapter stage makes it easy to connect a photovoltaic (PV) panel to a continuous load with a relatively high conversion efficiency and maximum power transfer. In this paper, the boost and buck converter are using, respectively, for tracking, the MPP and voltage control as illustrated in Figure 1.

\subsubsection{Modeling of the boost converter}

The operation of the boost converter is conditioned by a switching device, the latter can be MOSFET. If the duty cycle is $D$, during the period $0<t<D T$, the $\operatorname{Mosfet}\left(T_{1}\right)$ is open and the diode is reversed polarized. The voltage through the inductance $L_{l}$ is $V_{L l}=V_{\text {cin }}$. When $T_{l}$ is closed $(D T<t<T)$, the energy stored in the inductance is released by the diode in the output circuit $\left(V_{L I}=V_{\text {cin }}-V_{c}\right)[14,20]$. The expressions used to calculate the inductance $L_{l}$ and the capacitor $C$ of the boost converter (see Figure 1) are provided by:

$$
\begin{gathered}
V_{\text {out }}=V_{c}=\frac{V_{\text {cin }}}{(1-D)} \\
I_{\text {out }}=I_{c}=(1-D) I_{\text {cin }} \\
L_{1}=\frac{V_{\text {cin }} \times D}{\Delta I_{L 1} \times f_{s}}
\end{gathered}
$$

$$
C=\frac{I_{\text {out }} \times D}{\Delta V_{\text {out }} \times f_{s}}
$$

where, $V_{\text {cin }}$ and $V_{\text {out }}$ are respectively, the input and output voltage, $\Delta L_{L 1}$ and $\Delta V_{\text {out }}$ are respectively, an estimation of inductor and output ripple voltage, $f_{s}$ is switch frequency.

The value of the boost inductance is $290 \mu \mathrm{H}$, the capacitors of the input and output filters are $250 \mu \mathrm{F}$ and $330 \mu \mathrm{F}$ respectively. The switching frequency used is $10 \mathrm{kHz}$.

\subsubsection{Modeling of the buck converter}

The conversion of a lower output voltage than the input voltage is a specific feature of the buck converter. The MOSFET $\left(T_{2}\right)$ is operating in the range $0<t<D T$ and the diode is polarized in reverse. The inductance is charged with a voltage of $V_{L 2}=V_{c}-V_{\text {cout }}$ in the range $D T<t<T$, the MOSFET is in the off state and the diode is conductive $[19,20]$. The expressions used to obtain the inductance $L_{2}$ and the capacitor $C$ of the buck converter (see Figure 1) are described by:

$$
\begin{gathered}
V_{\text {cout }}=D \times V_{c} \\
L_{2}=\frac{V_{\text {cout }} \times(1-D)}{\Delta I_{L 2} \times f_{s}} \\
C=\frac{V_{\text {cout }} \times(1-D)}{8 \times L_{2} \times \Delta V_{\text {cout }} \times f_{s}}
\end{gathered}
$$

where, $V_{c}$ and $V_{\text {cout }}$ are respectively, the input and output voltage, $\Delta L_{L 2}$ and $\Delta V_{\text {cout }}$ are respectively, an estimation of inductor and output ripple voltage, $f_{s}$ is switch frequency.

The value of the buck inductance is $290 \mu \mathrm{H}$, the capacitor output filter is $330 \mu \mathrm{F}$ and the switching frequency used is 10 $\mathrm{kHz}$.

\section{ADAPTIVE FUZZY LOGIC}

Lotfi Aliasker Zadeh in 1965 introduced the theory of fuzzy sets, which are the basis of fuzzy logic. One of the characteristics of this intelligent technique is the use of linguistic rather than numerical variables $[11,21,22]$. In this subsection, we will discuss the definition of the proposed intelligent control systems according to the principles of fuzzy logic.

\subsection{Adaptive fuzzy logic MPPT algorithms}

In previous years, conventional Maximum Power Point Tracking (MPPT) algorithms have been increasingly neglected at the expense of MPPT algorithms based on artificial intelligence. The latter have good efficiency, a very good and fast response, without exceeding and less significant fluctuations during the fast changes of irradiation and temperature. For its implementation, the MPPT technique based on Fuzzy Logic has the advantage of working with imprecise inputs, without the need for an exact mathematical model to manage the non-linearity of the photovoltaic system. In most of the literature, a Fuzzy Logic-based MPPT with two inputs and one output has been proposed. In this section, the two input variables used are the error $E(k)$ and the variation of the error $C E(k)$ which are provided by $[7,14,15]$ : 


$$
\begin{gathered}
E(k)=\frac{\Delta P_{p v}}{\Delta V_{p v}}=\frac{P_{p v}(k)-P_{p v}(k-1)}{V_{p v}(k)-V_{p v}(k-1)} \\
C E(k)=E(k)-E(k-1)
\end{gathered}
$$

where, $P p v(k)$ and $V p v(k)$ are the power and the voltage of the photovoltaic panel respectively.

By analyzing the power-voltage $(P-V)$ characteristic curve in Figure 3, the position of the load operating point at time $k$ (either to the right or left of the Maximum Power Point) is determined by the input error $E(k)$. The direction of displacement of this point is indicated by the input change of error $C E(k)$.

In this article, the technique implemented with the fuzzy combination law of the Max-min operation is that of Mamdani. Figure 4 shows the diffrent parts of Fuzzy Logic Controller (FLC). It is structured into three main basic parts: Fuzzification, basic rule and defuzzification.

Fuzzification is an important concept in the Fuzzy Logic theory. Fuzzification is the process where the crisp quantities are converted to fuzzy (crisp to fuzzy). By identifying some of the uncertainties present in the crisp values, we form the fuzzy values (see Figure 5). The conversion of fuzzy values is represented by the membership functions.

In this study, membership function values are assigned to the linguistic variables using seven fuzzy subsets: $N F$ (Negative Huge), $N W$ (Negative Average), NL (Negative Little), $Z$ (zero), $P L$ (Positive Little), $P W$ (Positive Average) and $P F$ (Positive Huge). The partitions of fuzzy subsets and the shape of membership functions are shown in Figure 5. It should be noted that the number and shape of the membership functions were initially selected based on trial and error and in such a way that the regions of interest are covered appropriately by the input data. The control rules are indicated in Table 2 with $E$ and $C E$ as inputs and duty cycle $d D$ as the output. In addition, the control surface of Fuzzy model is shown in Figure 6. The reason of defining these rules is to achieve a proper duty cycle in each situation.

Inference rules: This method involves the knowledge to perform deductive reasoning. The membership function is formed from the facts known and knowledge. Let us use inference method for the identification of the triangle.

An example of a check rule from Table 2 can be read as follows: if $E$ is Zero(Z) and $C E$ is Positive Little (PL) then $d D$ is Positive Little (PL).

Defuzzification consists of converting the output of the linguistic variable into a precise numeric variable. Defuzzification uses the center of gravity to calculate the output of the FLC which is the duty cycle $(D)$.

$$
D=\frac{\sum_{j=1}^{n} \mu\left(D_{j}\right)-D_{j}}{\sum_{j=1}^{n} \mu\left(D_{j}\right)}
$$

where, $D_{j}$ is a numerical value understandable by the external environment (in our case $\Delta V_{p v}$ ).

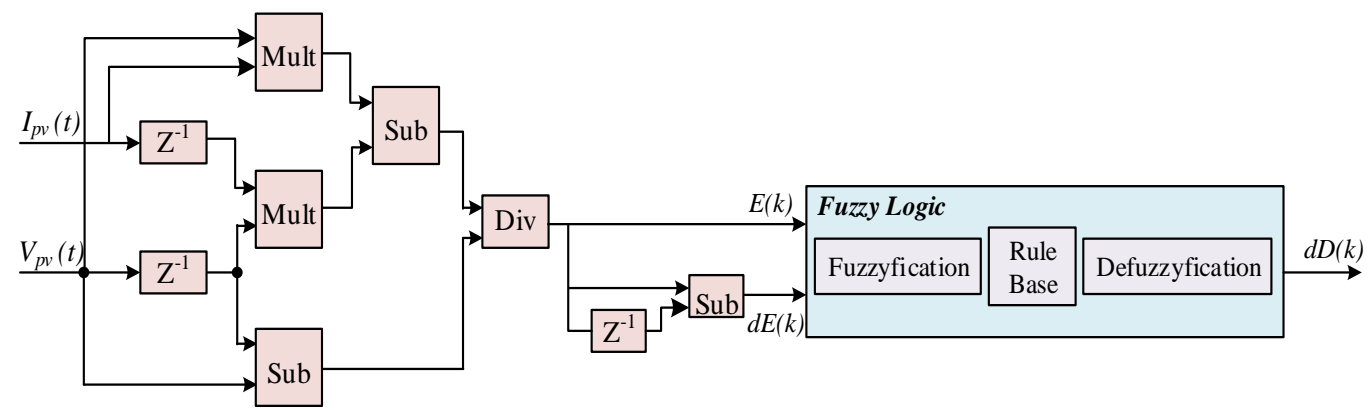

Figure 4. Fuzzy Logic-based scheme for Maximum Power Point Tracking (MPPT)

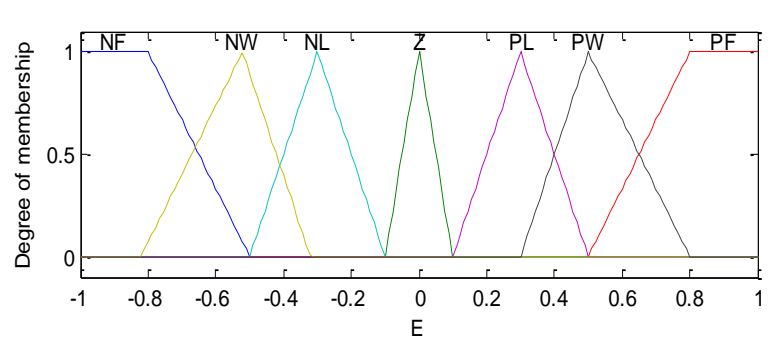

(a)

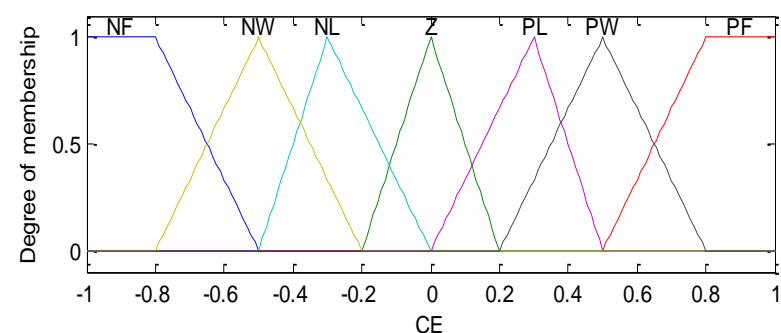

(b)

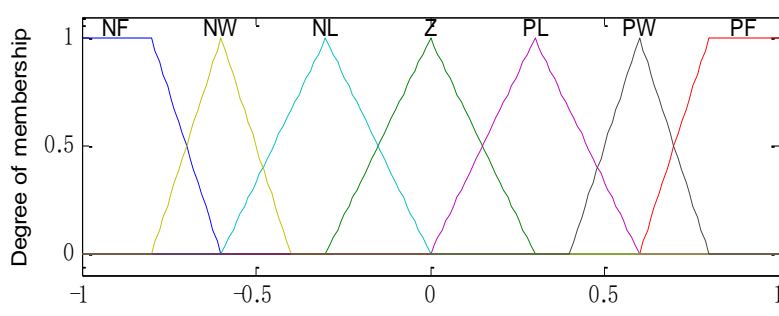

(c)

Figure 5. Membership functions, (a) for input $E(k)$, (b) for input $C E(k)$, and (c) for output $d D$ 
Table 2. FLC matrix rules

\begin{tabular}{|c|c|c|c|c|c|c|c|c|}
\hline & \multicolumn{7}{|c|}{ CE } \\
\hline & & $\mathrm{NF}$ & NW & NL & Z & PL & PW & PF \\
\hline \multirow{7}{*}{$\mathbf{E}$} & $\mathrm{NF}$ & $\mathrm{NF}$ & $\mathrm{NF}$ & NF & NW & NW & NL & Z \\
\hline & NW & $\mathrm{NF}$ & NF & NW & NW & NL & Z & PL \\
\hline & NL & $\mathrm{NF}$ & $\mathrm{NM}$ & $\mathrm{NM}$ & NL & Z & PL & PW \\
\hline & $\mathrm{Z}$ & NM & NM & NL & Z & PL & PW & PW \\
\hline & PL & NM & NL & Z & PL & PW & PW & $\mathrm{PF}$ \\
\hline & PW & $\mathrm{NL}$ & Z & PL & PW & PM & PF & PF \\
\hline & PF & Z & PL & PW & PW & PF & PF & PF \\
\hline
\end{tabular}

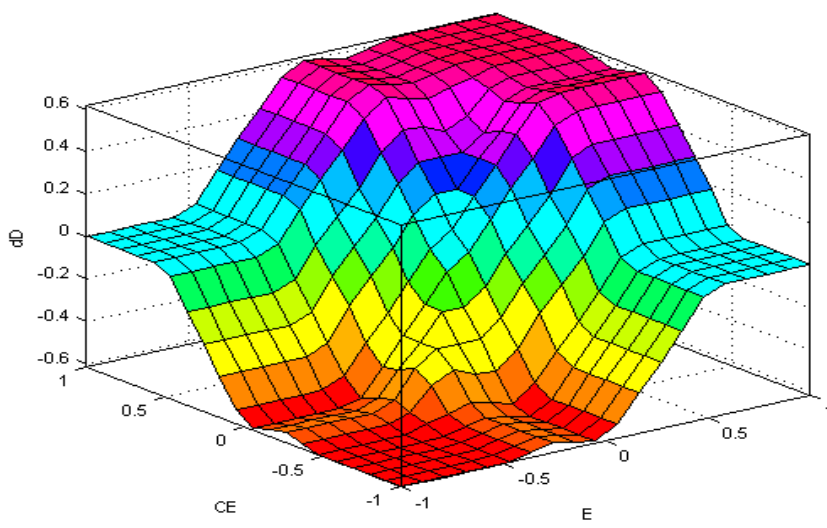

Figure 6. Three-dimensional surface corresponding to the membership in Figure 5 and the rule in Table 2

\subsection{Proposed adaptive Fuzzy Logic Control of Buck converter}

In recent years, numerous publications have highlighted the good dynamic performance of Fuzzy Logic Controllercontrolled systems. In this Section, we will focus on regulating the voltage of the Buck converter, the block diagram of which is illustrated in Figure 7. The buck converter will be controlled in current mode, the non-linear load will consist of a variable resistance. In this case, we will perform a cascade type Fuzzy Logic voltage control.

\subsection{1 e(k) and de(k) input}

Consider the Fuzzy Mamdani controller with two inputs and one output described in the previous section. The two inputs for voltage control at the output of the buck converter defined by Eqns. (14) and (15) respectively represent the error and the error variation.

$$
\begin{aligned}
& e(k)=V_{r e f}(k)-V_{m}(k) \\
& d e(k)=e(k)-e(k-1)
\end{aligned}
$$

\subsubsection{The input normalization}

The Fuzzy Logic Controller handles normalized input (domain [-1 1]). Generally, the value of $e_{n}$ is fixed and $d e_{n}$ is used as an optimization parameter as given by:

$$
\begin{array}{r}
e^{\prime}(k)=\max \left\{-1, \min \left[\frac{e(k)}{e_{n}}, 1\right]\right\} \\
d e^{\prime}(k)=\max \left\{-1, \min \left[\frac{d e(k)}{d e_{n}}, 1\right]\right\}
\end{array}
$$

\subsubsection{Fuzzy Logic Controller}

A Fuzzy Logic Controller defines the change in the duty cycle as defined by Eq. (18). The design of the Fuzzy Logic systems is presented in the next section.

$$
\Delta u_{c}(k)^{\prime}=f\left\{e^{\prime}(k), d e^{\prime}(k)\right\}
$$

\subsubsection{Fuzzy Logic Controller output renormalization}

The output of the Fuzzy Logic Controller is deformalized using factor $g_{m}$, to obtain the relative change in the duty cycle as given by:

$$
\Delta u(k)=\Delta u(k)^{\prime} g_{m}
$$

\subsubsection{Controller output, duty cycle}

Finally, the relative change is integrated to find the duty cycle of the converter by using an integrator as defined by:

$$
u(k)=\max \left\{0, \min \left(1, u(k-1)+\Delta u(k) T_{e c h}\right)\right\}
$$

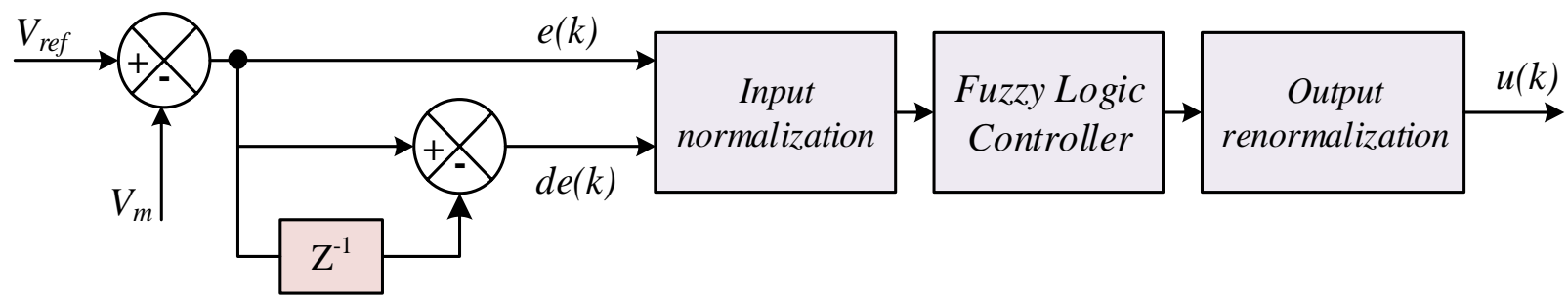

Figure 7. DC-DC power converter voltage controller

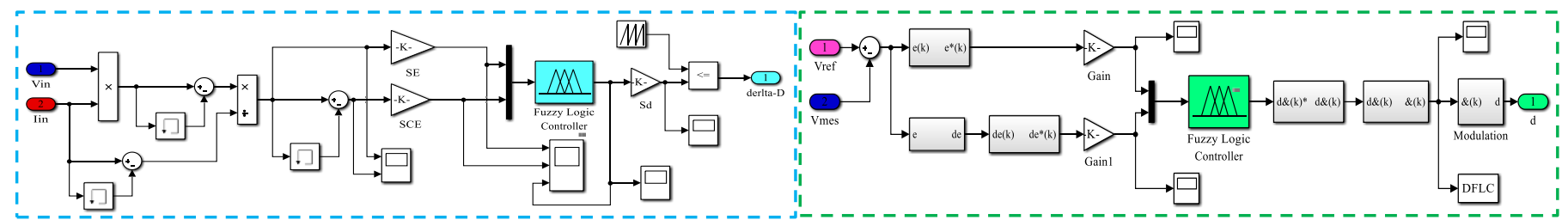




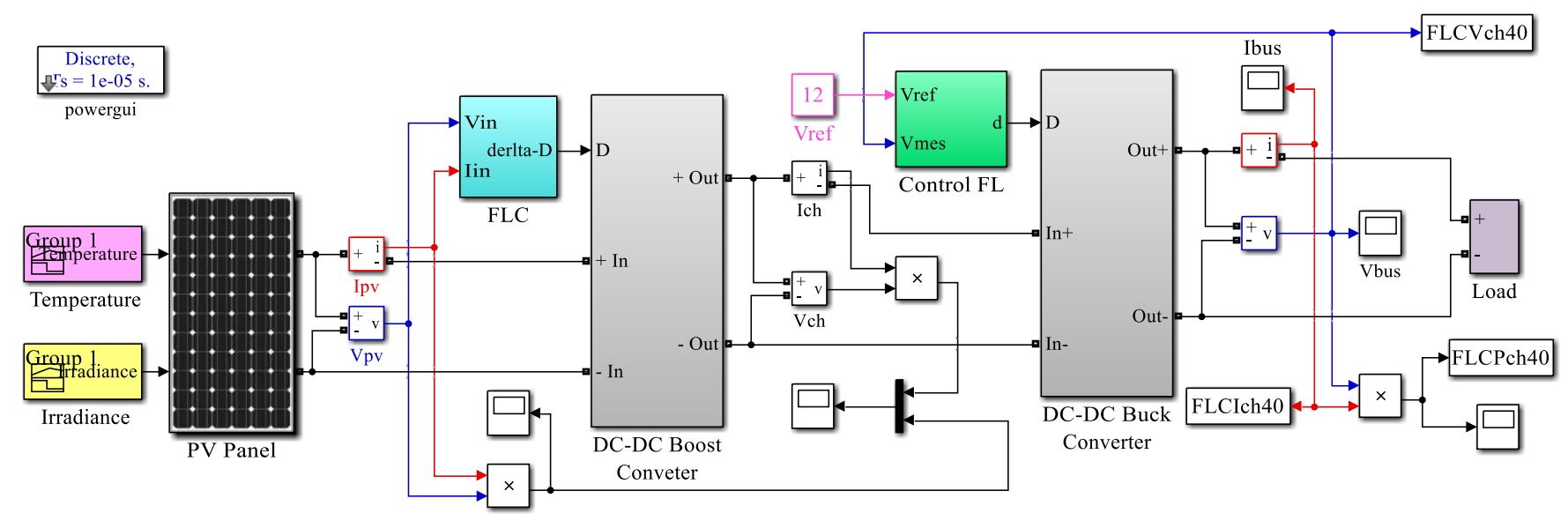

Figure 8. Proposed simulink model of PV system MPPT algorithm and voltage control with fuzzy logic

\section{SIMULATION RESULTS AND DISCUSSIONS}

Figure 8 shows the obtained global diagram Simulink model of photovoltaic (PV) system with Maximum Power Point Tracking (MPPT) algorithm and voltage control with Fuzzy Logic. The model was implemented and simulated in the MatLab/Simulink environment.

In Figure 8, the block diagram of the stand-alone PV system consists of a solar panel as the power source for the system. Then, the first DC-DC Boost converter with its MPPT control provides the maximum available power and serves as an interface between the solar panel and the next converter. And finally, the second Buck DC-DC converter with its Fuzzy Logic based voltage regulator serves as an interface between the variable load and the previous converter. The converter with its MPPT control uses the $V_{p v}$ voltage and $I_{p v}$ current supplied by the PV panel as inputs. Then the Pulse Width Modulation (PWM) signal generated by the MPPT control is used to drive the DC-DC boost converter. The voltage control based on Fuzzy Logic uses the voltage supplied by the Buck DC-DC converter and the voltage reference to generate the PWM signal to drive the Buck DC-DC converter.

\subsection{Analysis of FLC based MPPT algorithm}

The European Dynamic Energy Efficiency Test Standard EN 50530 specifies a test procedure for evaluating the effectiveness of maximum power point tracking (MPPT) systems. Figure 9 shows the profile of Irradiance $(G)$ and Temperature (T) used to assess the MPPT algorithm. Initially, $\mathrm{G}=1000 \mathrm{~W} / \mathrm{m}^{2}$ and $\mathrm{T}=25^{\circ} \mathrm{C}$, then $\mathrm{G}$ changes to $800 \mathrm{~W} / \mathrm{m}^{2}$ and $\mathrm{T}$ changes to $20^{\circ} \mathrm{C}$. G and $\mathrm{T}$ rise to $900 \mathrm{~W} / \mathrm{m}^{2}$ and $35^{\circ} \mathrm{C}$ respectively, then $\mathrm{G}$ drops to $750 \mathrm{~W} / \mathrm{m}^{2}$ when $\mathrm{T}$ passes $30^{\circ} \mathrm{C}$. Finally, $\mathrm{G}$ reaches $950 \mathrm{~W} / \mathrm{m}^{2}$ when $\mathrm{T}$ rises to $40^{\circ} \mathrm{C}$. These changes are performed every $0.2 \mathrm{~s}$ with a total simulation time of $1 \mathrm{~s}$.

In order to validate the effectiveness of the proposed method, the latter is tested using the Irradiance and Temperature profile illustrated in Figure 9. To demonstrate the response of the photovoltaic system to the simultaneous change in solar radiation and temperature, MatLab software was used to perform the simulations. Figure 10 shows the Maximum Power Point (MPP) pursuit of the proposed algorithm. It shows a fairy tale oscillation and a correct direction of MPP tracking.
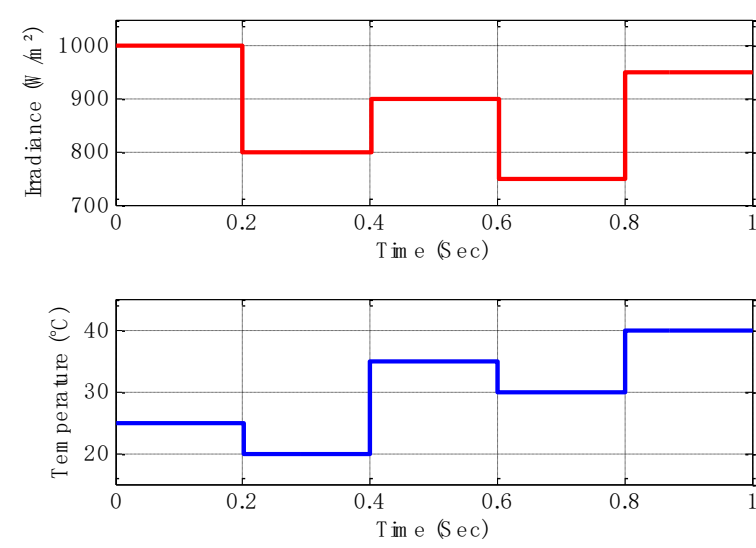

Figure 9. Profile of Irradiance and Temperature

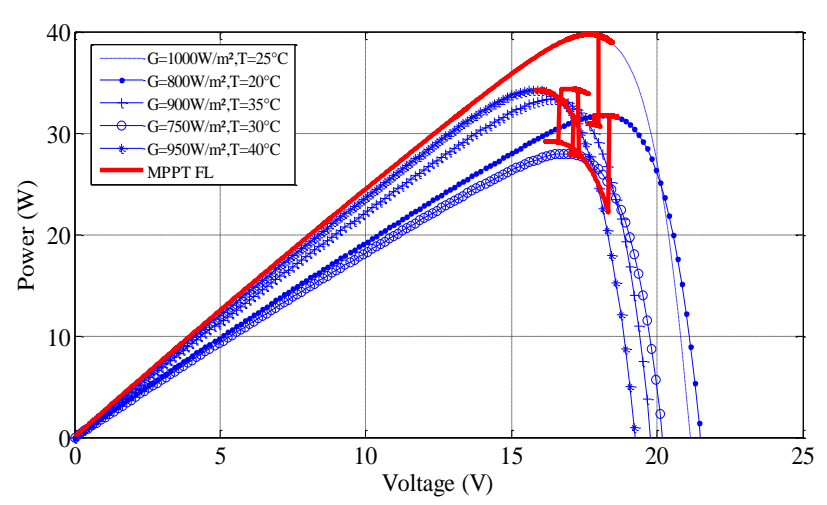

Figure 10. Maximum power point follow-up

The simulation results in Figure 11 show the waveforms of the photovoltaic (PV) panel power in red color $\left(P_{p v}\right.$ in Watt), in black color the PV panel voltage ( $V_{p v}$ in Volt), the loading voltage in blue color ( $V_{L}$ in Volt $)$ and in green color the current ( $I_{p v}$ in Ampere). The results in Figure 11 corroborate that the values of $P_{p v}, I_{p v}$ and $V_{p v}$ have reached the same values as those presented by the PV specifications in Figure 3 for a constant solar irradiation. The response time of the FLC-based MPPT algorithm is $5 \mathrm{~ms}$ and oscillates less in the dynamic regime. In addition, the change in irradiation significantly affects its differences in magnitude. The DC-DC boost converter used is corroborated by comparing the waveforms of the panel voltage and the load voltage. 


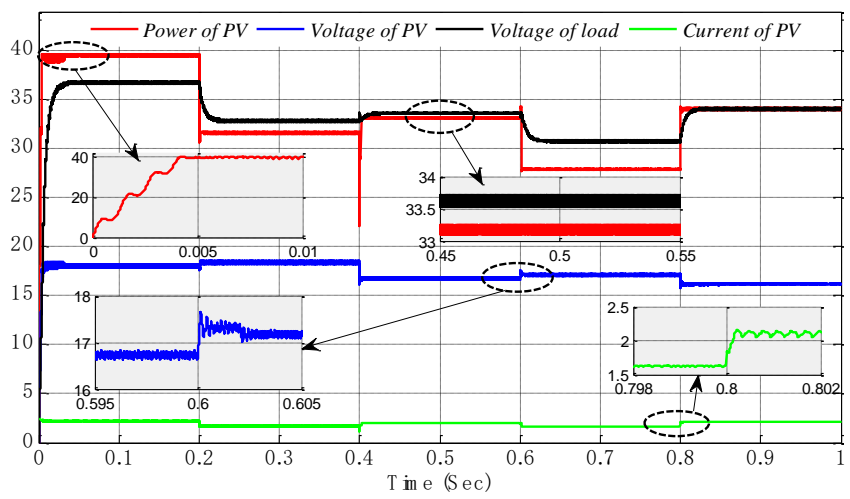

Figure 11. The results of the simulation of Fuzzy Logic Controller (FLC) based MPPT algorithm

\subsection{Response assessment of the buck converter with proposed adaptive fuzzy logic control}

With the standard settings of the Fuzzy Logic Controller (FLC) studied, whose role is to maintain a constant voltage of $12 \mathrm{~V}$ at the output of the buck converter despite simultaneous disturbances of the load and weather conditions (Temperature and irradiance). After simulation, we obtained the results presented in Figure 12.

During the simulation, an increment step of $0.1 \mathrm{~s}$ is imposed to vary the load from 25 to $35 \Omega$. The results in Figure 12 show a significant reduction in overshoot, adjustment time, peak amplitude and rising time.

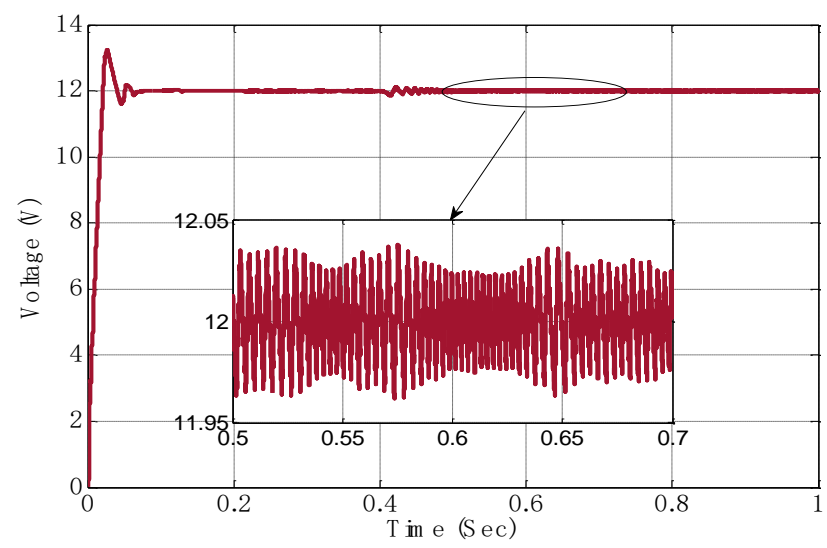

Figure 12. Response of buck converter

Table 3 shows the buck converter performance analysis under simulation conditions using the proposed Fuzzy Logic controller (FLC) adaptive control.

Table 3. Buck converter assessment

\begin{tabular}{cc}
\hline Parameters & Profile \\
\hline Amplitude of ridge $(\mathrm{V})$ & 12 \\
Rising time $(\mathrm{ms})$ & 2.1 \\
Settling time $(\mathrm{ms})$ & 20 \\
Overshoot $(\%)$ & 2 \\
\hline
\end{tabular}

\section{CONCLUSION}

An efficient use of photovoltaic (PV) solar energy requires electronic circuits associated with the conversion, control and conditioning of electrical energy. In this work, a system consisting of Maximum Power Point Tracking (MPPT) algorithm and a Fuzzy Logic-based voltage controller was designed. This system was implemented and observed under variable methodological conditions (irradiation and temperature) and load. The proposed Fuzzy Logic-based MPPT algorithm is able to find the Maximum Power Point (MPP) quickly and accurately without steady state oscillations. The latter extract the maximum power from the solar panel in accordance to the electrical characteristics of the PV module with excellent performance. The results of the output voltage of buck converter with Fuzzy Logic-based controller designed using the T-Standards and the standardization process have good transient control performance. In addition, this Fuzzy Logic Controller guarantees a DC voltage of $12 \mathrm{~V}$ at the output of the Buck converter and satisfactorily confirms the rejection of disturbances. The development of an experimental test bench for the proposed system will be carried out in future work in order to verify the simulation results.

\section{ACKNOWLEDGMENT}

The authors would like to express their gratitude to the Pierre-et-Jeanne Spiegel Foundation for its generous funding support.

\section{REFERENCES}

[1] Hyacinthe, T., Nzoundja, F.C.B., Kamta, M., HamanDjalo, Woafo, P. (2019). Experimental assessment of power consumption by a smart sun tracking system under variable weather conditions. Applied Solar Energy, 55(6): 385-396. https://doi.org/10.3103/S0003701X19060124

[2] Subudhi, B., Pradhan, R.R. (2013). A comparative study on maximum power point tracking techniques for photovoltaic power systems. IEEE Transactions Sustainable Energy, 4(1): 89-97. http://doi.org/10.1109/tste.2012.2202294

[3] Claude Bertin, N.F., Martin, K., Patrice, W. (2019). A comprehensive assessment of MPPT algorithms to optimal power extraction of a PV panel. Journal of Solar Energy Research, 4(3): 172-179. http://doi.org/10.22059/jser.2019.287029.1126

[4] Danandeh, M., Mousavi, S.M. (2018). Comparative and comprehensive review of maximum power point tracking methods for PV cells. Renewable and Sustainable Energy Reviews, $\quad 82$ : 2743-2767. http://doi.org/10.1016/j.rser.2017.10.009

[5] Kordestani, M., Mirzaee, A., Safavi, A.A., Saif, M. (2018). Maximum power point tracker (MPPT) for photovoltaic power systems - a systematic literature review. IEEE European Control Conference (ECC), Limassol, Cyprus, $\quad$ pp. 40-45. http://doi.org/10.23919/ecc.2018.8550117

[6] Meng, L., Shafiee, Q., Ferrari-Trecate, G., Karimi, H., Fulwani, D., Lu, X., Guerrero, J.M. (2017). Review on control of DC microgrids and multiple microgrid clusters. IEEE Journal of Emerging and Selected Topics in Power Electronics, $\quad 5(3)$ 928-948. http://doi.org/10.1109/jestpe.2017.2690219

[7] Rezk, H., Aly, M., Al-Dhaifallah, M., Shoyama, M. (2019). Design and hardware implementation of new 
adaptive fuzzy logic-based MPPT control method for photovoltaic applications. IEEE Access, 7: 106427106438. http://doi.org/10.1109/ACCESS.2019.2932694

[8] Boukenoui, R., Bradai, R., Mellit, A., Ghanes, M., Salhi, H. (2015). Comparative analysis of P\&O, modified hill climbing-FLC, and adaptive P\&O-FLC MPPTs for microgrid standalone PV system. 4th International Conference on Renewable Energy Research and Applications (ICRERA), Palermo, Italy, pp. 1095-1099. 22-25. https://doi.org/10.1109/ICRERA.2015.7418579

[9] Elgendy, M.A., Zahawi, B., Atkinson, D.J. (2013). Assessment of the incremental conductance maximum power point tracking algorithm. IEEE Transactions on Sustainable Energy, 4(1): 108-117. https://doi.org/10.1109/TSTE.2012.2202698

[10] Claude, Bertin, Nzoundja, F., Wira, P., Kamta, M., Badji, A., Tchakounte, H. (2019). Real-time experimental assessment of hill climbing MPPT algorithm enhanced by estimating a duty cycle for PV system. International Journal of Renewable Energy Research (IJRER), 9(3): 1180-1189.

[11] Robles, A.C., Taborda, G.J., Rodríguez, A.O. (2017). Fuzzy logic based MPPT controller for a PV system. $\begin{array}{lll}\text { Energies } & \text { (MDPI), } & 10(12):\end{array}$ https://doi.org/10.3390/en10122036

[12] Perry, A.G., Feng, G., Liu, Y.F., Sen P.C. (2007). A Design method for PI-like fuzzy logic controllers for DC-DC converter. IEEE Transactions on Industrial Electronics, 54(5): 2688-2696. http://doi.org/10.1109/tie.2007.899858

[13] Gehan, O., Pigeon, E., Menard, T., Pouliquen, M., Gualous, H., Slamani, Y., Tala-Ighil B. (2016). A nonlinear state feedback for DC/DC boost converters. Journal of Dynamic Systems, Measurement, and Control, American Society of Mechanical Engineers, 139(1): 118. http://doi.org/10.1115/1.4034602

[14] Yilmaz, U., Kircay, A., Borekci, S. (2018). PV system fuzzy logic MPPT method and PI control as a charge controller. Renewable and Sustainable Energy Reviews, 81: 994-1001. http://doi.org/10.1016/j.rser.2017.08.048

[15] Nzoundja Fapi C.B., Wira, P., Kamta, M. (2018). A fuzzy logic MPPT algorithm with a PI controller for a standalone PV system under variable weather and load conditions. IEEE International Conference on Applied Smart Systems (ICASS), Medea, Algeria, pp. 1-6. http://doi.org/10.1109/icass.2018.8652047

[16] Rai, N., Rai, B. (2018). Control of fuzzy logic based PVbattery hybrid system for stand-alone DC applications. Journal of Electrical Systems and Information Technology, 5(2): 135-143. http://doi.org/10.1016/j.jesit.2018.02.007

[17] Peyghami, S., Mokhtari, H., Blaabjerg, F. (2018). Autonomous power management in LVDC microgrids based on a superimposed frequency droop. IEEE Transactions on Power Electronics, 33(6): 1-10. http://doi.org/10.1109/tpel.2017.2731785

[18] Ma, G., Xu, G., Chen, Y., Ju, R. (2018). Voltage stability control method of electric springs based on adaptive PI controller. Electrical Power and Energy Systems, 95: 202-212. http://doi.org/10.1016/j.ijepes.2017.08.029

[19] Pathak, P.K., Yadav, A.K. (2019). Design of battery charging circuit through intelligent MPPT using SPV

system. Solar Energy, 178:

79-89.

http://doi.org/10.1016/j.solener.2018.12.018

[20] Reshma, Gopi, R., Sreejith, S. (2018). Converter topologies in photovoltaic applications - A review Renewable and Sustainable Energy Reviews, 94: 1-14. http://doi.org/10.1016/j.rser.2018.05.047

[21] Mamdani E.H., Assilian, S. (1975). An experiment in linguistic synthesis with a fuzzy logic controller. International Journal of Man-Machine Studies, 7(1): 113. http://doi.org/10.1016/s0020-7373(75)80002-2

[22] Issam, G., Sabir, M., Kamel, S., Mohamed, Y.T. (2019). A new adaptive neuro-fuzzy inference system (ANFIS) and PI controller to voltage regulation of power system equipped by wind turbine. European Journal of Electrical Engineering, 21(2): https://doi.org/10.18280/ejee.210204

\section{NOMENCLATURE}

a

$\mathrm{C}$

$\mathrm{D}$

$\mathrm{DC}$

$\mathrm{dE}$, de

E, e

FLC

$\mathrm{f}_{\mathrm{s}}$

G

$\mathrm{G}_{\mathrm{n}}$

I

$\mathrm{I}_{\mathrm{sc}}$

$\mathrm{K}$

$\mathrm{k}$

$\mathrm{K}_{\mathrm{i}}$

$\mathrm{K}_{\mathrm{V}}$

$\mathrm{L}_{1}$

$\mathrm{L}_{2}$

MPP

MPPT

NF

NL

NW

$\mathrm{PF}$

PL

PV

PW

PWM

q

$\mathrm{R}_{\mathrm{p}}$

$\mathrm{R}_{\mathrm{s}}$

STC

$\mathrm{T}$

$\mathrm{t}$

$\mathrm{T}_{\mathrm{n}}$

$\mathrm{V}$

$\mathrm{V}_{\mathrm{oc}}$

$\mathrm{V}_{\mathrm{t}}$

Z
Diode ideality factor

Capacitor

Duty cycle

Direct Current

Variation of the error

Error

Fuzzy Logic Controller

Switch frequency

Actual irradiation

Nominal irradiation

Output current of the PV panel

PV cell's short-circuit current

Boltzmann constant,

Sampling time

Current coefficient

voltage coefficient

Inductance of the boost converter

Inductance of the buck converter

Maximum Power Point

Maximum Power Point Tracking

Negative huge

Negative Little

Negative Average

Positive Huge

Positive Little

Photovoltaic

Positive Average

Pulse Width Modulation

Electron charge

Resistors parallel

Resistors series

Standard Test Conditions

Actual temperature.

Time

Nominal temperature

Output voltage across the PV panel

The cell's open circuit voltage at the nominal conditions

Thermal voltage

Zero 